\title{
Lipid accumulation product (LAP) was independently associated with obstructive sleep apnea in patients with type 2 diabetes mellitus
}

\author{
Lianqin Dong ${ }^{1 \dagger}$, Mingzhu Lin ${ }^{2,3+}$, Wengui Wang ${ }^{2+}$, Danyan Ma ${ }^{4}$, Yun Chen ${ }^{1}$, Weijuan Su ${ }^{2,3}$, Zheng Chen ${ }^{2,3}$,
} Shunhua Wang ${ }^{2,3}$, Xuejun $\mathrm{Li}^{2,3}$, Zhibin $\mathrm{Li}^{5^{*}}$ and Changqin $\mathrm{Liu}^{1,2,3^{*}}$ i

\begin{abstract}
Background: Lipid accumulation product (LAP) is a new index based on a combination of waist circumference (WC) and serum triglycerides (TG) reflecting lipid accumulation. In this cross-sectional study, we aimed to explore whether LAP was independently associated with obstructive sleep apnea (OSA) in Type 2 diabetes mellitus (T2DM) patients.

Methods: A cross-sectional study of 317 T2DM patients who underwent overnight polysomnography (PSG) tests was conducted. The clinical data between non-OSA group and OSA group were compared. Multivariable linear regression and multivariable logistic regression analyses were performed to determine associations of LAP, with apnea-hypopnea index (AHI) and OSA.

Results: Among 317 patients, 219 (69.1\%) were men, and the mean ages ( \pm SD) were 51.4 ( \pm 13.5 ) years for men and $54.6( \pm 15.1)$ years for women $(p=0.067)$. The prevalence rates of OSA were $63.0 \%$ for men and $68.4 \%$ for women ( $p=0.357$ ). LAP (log-transformed) was significantly correlated with AHI (log-transformed), with the Pearson's correlation coefficient of $0.170(p=0.002)$. With adjustment for potential confounding factors, multivariate linear regression analyses showed the association of LAP with AHI was not statistically significant, with the adjusted linear regression coefficients $(95 \% \mathrm{Cl})$ of per SD increase of LAP for AHI (log-transformed) was $0.092(-0.011-0.194, p=$ 0.080). Multivariate logistic regression analyses showed LAP was significantly associated with increased risk of OSA, with the adjusted OR $(95 \% \mathrm{Cl})$ of per SD increase of LAP of $1.639(1.032-2.604, p=0.036)$. However, as constituents of LAP, neither TG nor WC was significantly associated with AHI and OSA.
\end{abstract}

Conclusion: LAP was independently associated with OSA and might be used as a potential OSA risk marker in T2DM patients, beyond the general index of obesity.

Keywords: Obstructive sleep apnea, Lipid accumulation product, Apnea-hypopnea index, Type 2 diabetes mellitus

\footnotetext{
* Correspondence: zhibinli33@hotmail.com; liuchangqin@xmu.edu.cn

${ }^{\dagger}$ Lianqin Dong, Mingzhu Lin and Wengui Wang contributed equally to this

work.

${ }^{5}$ Epidemiology Research Unit, The First Affiliated Hospital of Xiamen

University, No.55 Zhenhai Road, Xiamen 361003, China

${ }^{1}$ The School of Clinical Medicine, Fujian Medical University, Fuzhou 350000,

China

Full list of author information is available at the end of the article
}

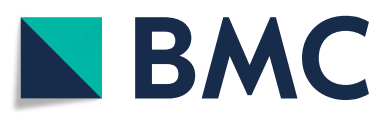

(0) The Author(s). 2020 Open Access This article is licensed under a Creative Commons Attribution 4.0 International License, which permits use, sharing, adaptation, distribution and reproduction in any medium or format, as long as you give appropriate credit to the original author(s) and the source, provide a link to the Creative Commons licence, and indicate if changes were made. The images or other third party material in this article are included in the article's Creative Commons licence, unless indicated otherwise in a credit line to the material. If material is not included in the article's Creative Commons licence and your intended use is not permitted by statutory regulation or exceeds the permitted use, you will need to obtain permission directly from the copyright holder. To view a copy of this licence, visit http://creativecommons.org/licenses/by/4.0/ The Creative Commons Public Domain Dedication waiver (http://creativecommons.org/publicdomain/zero/1.0/) applies to the data made available in this article, unless otherwise stated in a credit line to the data. 


\section{Introduction}

Obstructive sleep apnea (OSA) has gradually become a common sleep-disordered breathing in today's society $[1,2]$. OSA is characterized by the presence of repeated episodes of obstructive apnea and hypopnea during sleep [3]. Recent studied reported that the prevalence of moderate to severe OSA was $23.4 \%$ in women and $49.7 \%$ in men in the general population [4]. Patients with OSA often feel exhausted and sleepy during the daytime, which would result in the impairment in vigilance, concentration, cognitive function, social interactions and quality of life [5]. OSA usually develops in population who are overweight or obesity and is associated with hypertension and metabolic diseases [6]. Obesity is a prominent risk factor of OSA and increased visceral fat plays a role in the development of OSA [7], and weight control can effectively reduce the incidence of OSA in a longitudinal study [8]. In turns, sleep fragmentation and sleep restriction have been associated with increased food intake and consequent weight gain [9].

Type 2 diabetes mellitus (T2DM) is also a common disease around the world. Studies have shown that the prevalence rate of OSA is from 50 to $70 \%$ in diabetic patients [10]. Other studies also indicated a higher incidence rate of diabetes or insulin resistance in OSA patients [11]. OSA may induce diabetes through specific mechanisms such as glucose intolerance [12-14]. Data from murine models and human studies indicated that intermittent hypoxia and sleep fragmentation could result in the alternation of insulin sensitivity and glucose disposal [14]. Mok et al. showed that more severe OSA was associated with the poorer glycaemic control in T2DM patients expressed by the glycated hemoglobin A1c (HbA1c) levels after adjustment for age, race, sex, body mass index (BMI) and the duration of diabetes mellitus [11]. According to a study conducted by Nagayoshi and colleagues, they found that subjects with severe OSA were at greater risk of incident diabetes compared to persons classified as normal and independent of adiposity [14]. OSA has established a link with obesity and diabetes by the above reasons [9].

Rising BMI, waist circumference (WC), and neck circumference $(\mathrm{NC})$ are important risk factors for the development of OSA [15]. Lipid accumulation product (LAP) is a new index based on a combination of WC and serum triglycerides (TG) reflecting lipid accumulation, which has been used as a marker of obesity [16]. A study included 2524 non-diabetic patients from China suggested that LAP could better identify insulin resistance than BMI and WC [17]. In a cohort study included 4508 non-diabetic participants with a median age of 42 years, higher LAP trajectories were associated with an increased risk of diabetes [18]. In a 6-year follow-up prospective study, the researchers found that LAP was superior to BMI in predicting diabetes in young individuals [19]. In T2DM patients, LAP was a useful tool to predict the risk for chronic diabetic complications, such as diabetic retinopathy [20]. However, in a large crosssectional study with a total of 5539 subjects, Zou and colleagues also found LAP was of moderate efficiency in screening for OSA, which indicate that LAP is a simple and practical screening tool for OSA [21].

Epidemiological evidence indicate obesity could result in OSA via several mechanism including the collapsibility of the pharyngeal airway through excessive fat deposition [22], oxidative stress, inflammation, and even mutual organ interactions among the respiratory system, adipose tissue and intestine [23]. Similarly, OSA and T2DM share mutual risk factors such as obesity and insulin resistance [11]. However, there are few studies focusing on association between separate LAP and OSA prevalence in T2DM patients. Therefore, the aim of the present study was to investigate whether LAP is independently associated with the presence of OSA in T2DM.

\section{Methods \\ Study subjects}

During the period from 2013 to 2017, a total of 346 T2DM patients underwent overnight polysomnography (PSG) test had been recruited. Exclusion criteria were described as our previous study [24]. Of 346 patients, 317 patients who had complete data on clinical, PSG, and LAP were left for the present analysis. This study was approved by the Human Research Ethics Committee of the First Affiliated Hospital of Xiamen University (Xiamen, China).

\section{Demographic and biochemical measurements}

Demographic data including body weight, standing height, WC, Hip circumference (HC), and arterial blood pressure were collected as described as our previous report [24]. HbA1c, TG, Total cholesterol (TC), HDLcholesterol (HDL-c), and LDL-cholesterol (LDL-c) measurements have also been detailed described in the previous study [24]. BMI was calculated as follows: Body weight [kilograms] / (height $[\mathrm{m}])^{2}$. LAP was calculated as follows: (WC $[\mathrm{cm}]-65) \times(\mathrm{TG}$ concentration $[\mathrm{mmol} /$ L]) for men, and (WC $[\mathrm{cm}]-58) \times(\mathrm{TG}$ concentration $[\mathrm{mmol} / \mathrm{L}])$ for women, respectively [16].

\section{Polysomnography assessments}

Polysomnography (PSG) (PSG, Comp medics, Abbotsford, Australia) was recorded as same as described in the previous report [24] and was scored according to generally accepted scoring methods [25]. The apnea-hypopnea index (AHI) was defined as the total number of 
obstructive apnea and hypopnea per hour of sleep. OSA was defined as $\mathrm{AHI} \geq 5[5]$.

\section{Statistical analyses}

Data was presented as the mean \pm standard deviation or as median (inter-quartile range, IQR) for continuous variable or number and percentage for categorical variable. Normality of all continuous variables were conducted. AHI and LAP did not follow normal distributions and therefore log-transformation on AHI and LAP were performed. Differences between OSA and non-OSA groups were analyzed on continuous variables using Student's $t$ test ( $t$-test) for those with normal distribution and the Mann-Whitney $\mathrm{U}$ test for those with skewed distribution and on categorical variables using chi-square test. Pearson's correlation analysis is used to analysis the correlation between LAP (log-transformed) and AHI (log-transformed).

Multivariable linear regression was used to explore the association of LAP with AHI (log-transformed). And multivariable logistic regression analysis was used to calculate the adjusted odds ratios (OR) and 95\% confidence interval (CI) of LAP (per SD increase) for OSA in different models with adjustment for potential confounders. For both the multivariable linear regression and logistic regression analyses, no variables were adjusted for in model 1; age, sex, regular drinking, current smoking, T2DM duration, oral glucose-lowering agents (OGLA) and insulin use were adjusted for in model 2; systolic blood pressure (SBP), diastolic blood pressure (DBP), BMI, TC, LDL-c, and HbA1c were further adjusted for in model 3. To show if LAP was a better predictor than its two constitutes (TG and WC), additional regression analyses were further conducted for TG and WC separately and Akaike information criterions (AIC) were used to compare these consecutive models. A receiver operating characteristic (ROC) analysis was conducted for LAP to evaluate its ability to correctly detect moderatesevere OSA in T2DM patients. All $p$-values were twosided and $\mathrm{p}$-value $<0.05$ was considered statistically significant. All statistical analyses were performed using SPSS version 21.0 software (IBM Corporation, Armonk, NY).

Table 1 Demographic, lifestyle and clinical characteristics of study subjects

\begin{tabular}{|c|c|c|c|c|}
\hline & Total & None-OSA & OSA & $p$ value \\
\hline $\mathrm{n}(\%)$ & 317 & $112(35.3 \%)$ & $205(64.7 \%)$ & \\
\hline Age (years) & $52.4 \pm 14.1$ & $47.1 \pm 14.8$ & $55.3 \pm 12.8$ & $<0.001 \#$ \\
\hline Gender & & & & 0.357 \\
\hline Female $(n, \%)$ & 98 (30.9\%) & $31(27.7 \%)$ & 67 (32.7\%) & \\
\hline Male (n, \%) & 219 (69.1\%) & $81(72.3 \%)$ & $138(67.3 \%)$ & \\
\hline T2DM duration (years) & $4.0(1.0-10.0)$ & $3.0(0.6-8.0)$ & $4.0(1.0-10.0)$ & 0.056 \\
\hline Current smoking (\%) & 112 (35.3\%) & $40(35.7 \%)$ & $72(35.1 \%)$ & 0.916 \\
\hline Regular drinking (\%) & $100(31.5 \%)$ & $33(29.5 \%)$ & $67(32.7 \%)$ & 0.556 \\
\hline OGLA use (\%) & $249(78.5 \%)$ & $83(74.1 \%)$ & $166(81.0 \%)$ & 0.154 \\
\hline Stain use (\%) & $234(73.8 \%)$ & $71(63.3 \%)$ & $163(79.5 \%)$ & $0.001 \#$ \\
\hline Insulin use (\%) & $208(65.6 \%)$ & $76(67.9 \%)$ & $132(64.4 \%)$ & 0.283 \\
\hline $\mathrm{SBP}(\mathrm{mmHg})$ & $133 \pm 18$ & $131 \pm 17$ & $134 \pm 18$ & 0.058 \\
\hline $\mathrm{DBP}(\mathrm{mmHg})$ & $81 \pm 10$ & $79 \pm 10$ & $81 \pm 10$ & 0.071 \\
\hline $\mathrm{BMI}\left(\mathrm{kg} / \mathrm{m}^{2}\right)$ & $27.9 \pm 4.1$ & $27.3 \pm 4.2$ & $28.2 \pm 4.0$ & $0.039^{*}$ \\
\hline$W C(\mathrm{~cm})$ & $98.0 \pm 9.9$ & $95.3 \pm 9.8$ & $99.5 \pm 9.6$ & $<0.001 \#$ \\
\hline $\mathrm{HbA1c}(\%)$ & $9.9 \pm 2.2$ & $10.1 \pm 2.3$ & $9.8 \pm 2.2$ & 0.160 \\
\hline $\mathrm{TG}(\mathrm{mmol} / \mathrm{L})$ & $1.69(1.20-2.51)$ & $1.55(1.15-2.20)$ & $1.76(1.28-2.58)$ & $0.041^{*}$ \\
\hline $\mathrm{TC}(\mathrm{mmol} / \mathrm{L})$ & $5.2 \pm 1.1$ & $5.3 \pm 1.2$ & $5.1 \pm 1.1$ & 0.252 \\
\hline $\mathrm{HDL}-\mathrm{c}(\mathrm{mmol} / \mathrm{L})$ & $1.1 \pm 0.3$ & $1.1 \pm 0.2$ & $1.1 \pm 0.2$ & 0.244 \\
\hline LDL-c (mmol/L) & $3.1 \pm 1.1$ & $3.3 \pm 1.1$ & $3.1 \pm 1.0$ & $0.048^{*}$ \\
\hline AHI (events/h) & $9.2(3.4-25.5)$ & $2.0(0.9-3.8)$ & $19.8(9.7-34.6)$ & $<0.001 \#$ \\
\hline LAP & $60.8(37.2-94.0)$ & $52.8(31.2-84.3)$ & $69.2(42.1-98.2)$ & $0.001 \#$ \\
\hline
\end{tabular}

${ }^{*} p<0.05 ;{ }^{\#} p<0.01$

Data was presented as the mean \pm standard deviation or as median (interquartile range) for continuous variable or number and percentage for categorical variable

Abbreviations: T2DM type 2 diabetes mellitus, OGLA oral glucose-lowering agents, WC Waist circumference, $B M I$ body mass index, SBP systolic blood pressure, DBP diastolic blood pressure, TG Triglyceride, TC total cholesterol, HDL-c high-density lipoprotein cholesterol, LDL-c low-density lipoprotein cholesterol, $A H I$ apnea hypopnea index, OSA obstructive sleep apnea syndrome, LAP Lipid accumulation product 


\section{Results}

Among 317 patients with T2DM, 219 (69.1\%) were men, and the mean ages $( \pm \mathrm{SD})$ were $51.4( \pm 13.5)$ years for menand $54.6( \pm 15.1)$ years for women $(p=0.067)$. The prevalence rates of OSAwere $63.0 \%$ for men and $68.4 \%$ for women $(p=0.357)$.

\section{Demographic, lifestyle and clinical characteristics categorized by the severity of OSA}

Table 1 showed the demographic, lifestyle and clinical characteristics between non-OSA group and OSA group. There were significant differences in ages $(47.1 \pm 14.8$ vs. $55.3 \pm 12.8, p<0.001)$, statin use $(71(30.3 \%)$ vs. 163 (69.7\%), $p=0.006)$, WC $(95.3 \pm 9.8$ vs. $99.5 \pm 9.6, p<$ $0.001)$, BMI ( $27.3 \pm 4.2$ vs. $28.2 \pm 4.0, p=0.039)$, HbA1c $(10.1 \pm 2.3$ vs. $9.8 \pm 2.2, p=0.160)$, TG (median (IQR) $1.55(1.15-2.20)$ vs. $1.76(1.28-2.58), p=0.041)$, LDL-c (3.3 \pm 1.1 vs. $3.1 \pm 1.0, p=0.048)$, AHI (median (IQR) 2.0 (0.9-3.8) vs. 19.8 (9.7-34.6), $p<0.001$ ) and LAP (median (IQR) 52.8 (31.2-84.3) vs 69.2 (42.1-98.2), p < 0.001) between two groups. And there were no significant differences between non-OSA and OSA in T2DM duration, gender, current smoking, regular drinking, OGLA use, statin use, insulin use, SBP, DBP, TC and LDL-c.

\section{Correlation of LAP with AHI}

Pearson's correlation analysis was performed to explore the correlation of LAP (log-transformed) with AHI (logtransformed). Figure 1 showed that LAP was significantly and positively correlated with AHI, with the Pearson's correlation coefficient of $0.170(p=0.002)$.

\section{Association of LAP with AHI}

Multivariate linear regression analyses were performed to show the independent association of LAP with AHI (Table 2). In model 1 , model 2 and model 3 with adjustment for the same confounding factors as OSA, the adjusted linear regression coefficients $(95 \% \mathrm{CI})$ of per SD increase of LAP for AHI (log-transformed) were $0.100(0.032-0.169, p=0.004), 0.121(0.052-0.191, p=$ $0.001)$ and $0.092(-0.011-0.194, p=0.080)$, respectively. Similar to logistic regression analyses on OSA, the full models (models 3 ) showed neither TG nor WC was significantly associated with AHI. Akaike information criterion (AIC) of multivariate linear regression analyses of TG, WC and LAP in model 3 were 543.5, 543.9 and 541.6, respectively.

\section{Association of LAP with OSA}

Multivariate logistic regression analyses were performed to show the independent association of LAP with OSA (Table 2). In model 1 without any adjustment, the adjusted OR (95\% CI) of per SD increase of LAP for OSA was1.520 (1.159-1.995, $p=0.003)$. In model 2 and model 3 with the same adjustments as those in multivariable linear regression analyses, the association of LAP with OSA was still statistically significant, with the adjusted OR $(95 \% \mathrm{CI})$ of per SD increase of LAP of $1.752(1.273$ $2.413, p=0.001)$ and $1.639(1.032-2.604, p=0.036)$, respectively. Additional multivariate logistic regression analyses were also performed to show the independent associations of OSA with the two constitutes of LAP (TG and WC). In the full models (models 3 ) with adjustment for potential confounding factors, neither TG nor WC was significantly associated with OSA; and the adjusted ORs (95\%CI) were $1.352(0.876-2.085)$ and 1.038 (0.989-1.090) (both $p$-values $>0.05)$. AIC were 382.0, 381.1 and 379.7 for TG, WC and LAP in model 3, respectively.

Further, ROC analysis was used to determine the suggested cutoff values of LAP for moderate-severe OSA. The area under the ROC curve (AUROC) (95\%CI) for LAP was $0.631(0.569-0.693, p<0.001)$. The best cut-off

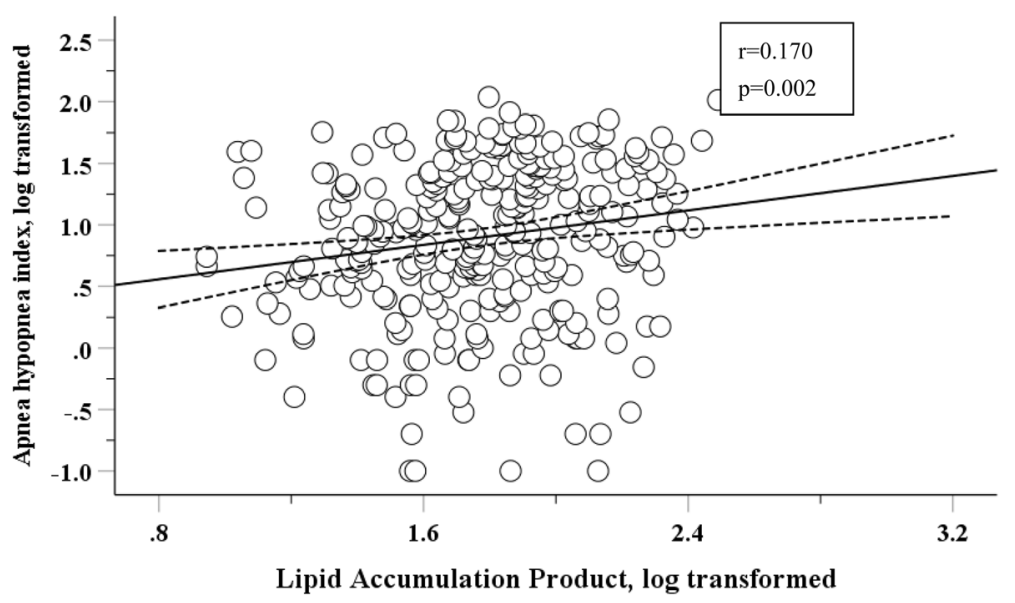

Fig. 1 Correlation of LAP (log-transformed) with AHI (log-transformed) in patients with T2DM 
Table 2 Associations of TG, WC and LAP with AHI and OSA in patients with T2DM

\begin{tabular}{|c|c|c|c|c|c|c|}
\hline & \multicolumn{3}{|c|}{ Linear regression on Log (AHI) } & \multicolumn{3}{|c|}{ Logistic regression on OSA } \\
\hline & Coefficient & $95 \% \mathrm{Cl}$ & $P$ value & ORs & $95 \% \mathrm{Cl}$ & $P$ value \\
\hline \multicolumn{7}{|l|}{ TG } \\
\hline Model 1 & 0.029 & -0.040 to 0.099 & 0.406 & 1.242 & 0.965 to 1.599 & 0.092 \\
\hline Model 2 & 0.043 & -0.027 to 0.113 & 0.227 & 1.336 & 1.007 to 1.773 & 0.045 \\
\hline Model 3 & 0.060 & -0.041 to 0.160 & 0.244 & 1.352 & 0.876 to 2.085 & 0.173 \\
\hline \multicolumn{7}{|l|}{ WC } \\
\hline Model 1 & 0.019 & 0.013 to 0.026 & $<0.001$ & 1.048 & 1.021 to 1.075 & $<0.001$ \\
\hline Model 2 & 0.022 & 0.016 to 0.029 & $<0.001$ & 1.067 & 1.036 to 1.099 & $<0.001$ \\
\hline Model 3 & 0.008 & -0.004 to 0.019 & 0.186 & 1.038 & 0.989 to 1.090 & 0.133 \\
\hline \multicolumn{7}{|l|}{ LAP } \\
\hline Model 1 & 0.100 & 0.032 to 0.169 & 0.004 & 1.520 & 1.159 to 1.995 & 0.003 \\
\hline Model 2 & 0.121 & 0.052 to 0.191 & 0.001 & 1.752 & 1.273 to 2.413 & 0.001 \\
\hline Model 3 & 0.092 & -0.011 to 0.194 & 0.080 & 1.639 & 1.032 to 2.604 & 0.036 \\
\hline
\end{tabular}

AHI was log-transformed

Model 1 was not adjusted

Model 2 was adjusted for age, gender, T2DM duration, regular drinking, current smoking, OGLA, statin use, and insulin use

Model 3 was further adjusted for BMI, SBP, DBP, TC, LDL-C, HbA1C

Abbreviations: T2DM type 2 diabetes mellitus, OGLA oral glucose-lowering agents, WC Waist circumference, $B M I$ body mass index, SBP systolic blood pressure, $D B P$ diastolic blood pressure, TG Triglyceride, $T C$ total cholesterol, $H D L$-c high-density lipoprotein cholesterol, $L D L-c$ low-density lipoprotein cholesterol, $A H I$ apnea hypopnea index, OSA obstructive sleep apnea syndrome, LAP Lipid accumulation product

points of LAP to detect moderate-severe OSA was 40.77 (Youden's index $=0.254$ ) (Fig. 2).

\section{Discussion}

In the current study, we found that the prevalence rates of OSA were $63.0 \%$ for men, and $68.4 \%$ for women in this diabetic patient'scohort. LAP was significantly correlated with

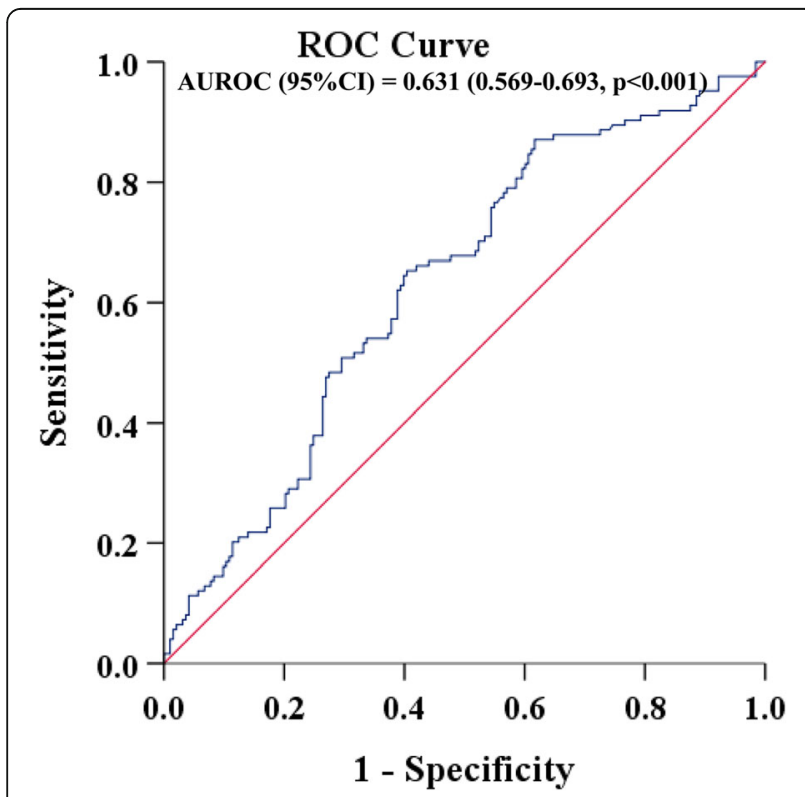

Fig. 2 Receiver operating characteristic curves and area under receiver operating characteristic curves (AUROCs) for the detection of moderate-severe OSA using LAP
AHI. Furthermore, LAP was significantly associated with OSA after adjusting for potential confounding factors in both linear regression and logistic regression analyses. However, with adjustment for same confounding factors, as constituents of LAP, neither TG nor WC was significantly associated with AHI and OSA. Our results indicated that LAP was independently associated with the risk of OSA.

There is a bidirectional association between OSA and T2DM $[4,26]$. OSA is characterized by the intermittent hypoxemia through repeated upper airway collapse. The repeated episodes of obstructive apnea and hypopnea would lead to metabolic disorders such as insulin resistance, impairment of glucose tolerance and development of T2DM [14], which eventually lead to diabetes and cardiovascular disease [27, 28]. A recent meta-analysis of nine longitudinal cohort studies included 64,101 participants from various geographic regions, with a follow-up duration between 2.7 and 16 years, revealed that OSA is associated with incident diabetes, with an adjusted pooled relative risk of 1.35 [4]. Conversely, individuals with diabetes also increase the risk of developing OSA. In a population-based study including three ongoing prospective U.S. cohorts, the researchers observed a $43 \%$ higher OSA risk among individuals with diabetes after adjusting for adiposity [26]. In another study, T2DM have an almost 50\% increase in risk of developing OSA compared with patients without T2DM, independent of potential confounders and traditional OSA risk factors [29]. Overweight / obesity is one of important causative factors of both OSA and T2DM, and shared the risk factors for both OSA and T2DM [30]. 
In terms of AHI and insulin resistance, the severity of OSA is both associated with visceral obesity rather than BMI [31]. Similarly, visceral fat has been associated with increased risk of OSA in those with T2DM [32]. In type 2 diabetic patients with poor diabetic control, OSA is highly prevalent and related to abdominal obesity [33]. A recent crosssectional study indicated that high value of either WC or waist-to-height ratio is associated with the presence and severity of OSA [34]. Magnetic resonance imaging (MRI) and computed tomography $(\mathrm{CT})$ are the gold standards we know for measuring visceral fat. It is difficult to be widely used because of its high cost [35]. LAP is a simple indicator thatrequires only the serum triglycerides level and an anthropometric factor (WC), which can accurately differentiate between visceral adiposity and subcutaneousadiposity by describing over accumulation of fat mass [36]. Previous studies reveal LAP is often used to predict and identify diseases such as diabetes, metabolism syndrome, polycystic ovary syndrome and CVD [16, 19, 37-39]. A recent large crosssectional study shows that LAP has a modest effect in screening OSA [21]. BMI is extensively used as the generally marker of global adiposity. However, in the current study after adjusting for potential confounding factors, even BMI, we found that LAP was still independently associated the risk of OSA in patients with T2DM. There may be several potential mechanisms for LAP in association with the risk of OSA. Firstly, comparing with the other surrogates such as TG/ HDL-C ratio, visceral adiposity index (VAI), TG, fasting glucose (TyG) index, LAP had better association with insulinstimulated glucose disposal and higher ability to detect insulin resistance with insulin sensitivity assessed by hyperinsulinemic euglycemic clamp [40]; Secondly, longitudinal trajectories of LAP, which reflect the efficacy of patients' lipid-lowering treatment and lifestyle improvement, has an independent effect on 5-year T2DM incidence beyond LAP measured at baseline [18].

There are some limitations in the present study. First, this is a cross-sectionalstudyand no causal relationship can be drawn. Further prospectivecohort studies are needed to confirm the precise relationship between LAP and OSA in T2DM patients. Second, the sample size of studywas relatively smalland we might not have sufficient power. Third, the participants of our study come from the hospitalized patients with poor controlled glycemia, which cannot represent the general population.

\section{Conclusion}

In conclusion, we found that LAP, a combination index of waist circumference and triglycerides, is independently associated with OSA, even with adjustment for BMI and other potential confounding factors, and therefore could be used as a potential OSA risk marker in T2DM patients, beyond the general index of obesity.
Acknowledgements

We are grateful to all the patients for their participation.

\section{Authors' contributions}

The study concept and design were framed by $L D, M L, Z L$ and $C L$. LD, WW, DM, YC, WS, ZCand SW collected data. LD, ZL and CL conducted the statistical data analysis and drafted the manuscript. ML, DM, ZL and $\mathrm{CL}$ contributed to discussion and revision. All authors read and approved the final manuscript.

\section{Funding}

This work was supported by grants 2017 J01365 for the natural science foundation of Fujian province and grants 81870611 for the natural science foundation of China.

\section{Availability of data and materials}

The datasets used and / or analyzed during the current study are available from the corresponding author on reasonable request.

\section{Ethics approval and consent to participate}

The study was approved by the institutional review board in accordance with the ethical standards established by ethics committee of the First Affiliated Hospital of Xiamen University. Written informed consent was obtained from all participants.

\section{Consent for publication}

Not applicable.

\section{Competing interests}

The authors declare that they have no competing interests.

\section{Author details}

${ }^{1}$ The School of Clinical Medicine, Fujian Medical University, Fuzhou 350000, China. ${ }^{2}$ Department of Endocrinology and Diabetes, The First Affiliated Hospital of Xiamen University, No.55 Zhenhai Road, Xaimen 361003, China.

${ }^{3}$ Xiamen Clinical Medical Center for Endocrine and Metabolic Diseases, Fujian Province Key Laboratory of Diabetes Translational Medicine, Xiamen, China.

${ }^{4}$ School of Medicine, Xiamen University, Xiamen, China. ${ }^{5}$ Epidemiology Research Unit, The First Affiliated Hospital of Xiamen University, No.55

Zhenhai Road, Xiamen 361003, China.

Received: 19 July 2020 Accepted: 3 December 2020

Published online: 09 December 2020

\section{References}

1. Lee W, Nagubadi S, Kryger MH, Mokhlesi B. Epidemiology of obstructive sleep apnea: a population-based perspective. Expert Rev Respir Med. 2008; 2(3):349-64 PMID: 19690624

2. Young T, Palta M, Dempsey J, Skatrud J, Weber S, Badr S. The occurrence of sleep-disordered breathing among middle-aged adults. N Engl J Med. 1993; 328:1230-5 PMID: 8464434.

3. Bruyneel M, Kleynen P, Poppe K. Prevalence of undiagnosed glucose intolerance and type 2 diabetes in patients with moderate-to-severe obstructive sleep apnea syndrome. Sleep Breath. 2019. https://doi.org/10. 1007/s11325-019-01989-y PMID: 31838624.

4. Heinzer R, Vat S, Marques-Vidal P, Marti-Soler H, Andries D, Tobback N, Mooser V, Preisig M, Malhotra A, Waeber G, Vollenweider P, Tafti M, HabaRubio J. Prevalence of sleep-disordered breathing in the general population: the HypnoLaus study. Lancet Respir Med. 2015;3(4):310-8 PMID: 25682233.

5. Kapur VK, Auckley DH, Chowdhuri S, Kuhlmann DC, Mehra R, Ramar K Harrod CG. Clinical Practice Guideline for Diagnostic Testing for Adult Obstructive Sleep Apnea: An American Academy of Sleep Medicine Clinical Practice Guideline. J Clin Sleep Med. 2017;13(3):479-504 PMID: 28162150.

6. Zheng C, Song H, Wang S, Liu J, Lin T, Du C, Xie H, Chen Z, Zheng S, Li Z, et al. Serum Uric Acid Is Independently Associated with Risk of Obstructive Sleep Apnea-Hypopnea Syndrome in Chinese Patients with Type 2 Diabetes. Dis Markers. 2019;2019:4578327. https://doi.org/10.1155/2019/ 4578327 PMID: 31281547.

7. Cetin N, Günes Tatar I, Yüceege M, Ergun O, Hekimoğlu B. Ultrasonographic evaluation of abdominal wall fat index, carotid intima-media thickness and 
plaque score in obstructive sleep apnea syndrome. Med Ultrason. Med Ultrason. 2019;21(4):422-6 PMID: 31765450.

8. Peppard PE, Young T, Palta M, et al. Longitudinal study of moderate weight change and sleep-disordered breathing. JAMA. 2000;284:3015-21 PMID: 11122588 .

9. Singh P, Somers VK. Obstructive sleep apnea, diabetes, and obesity: partners in crime? Sleep Med. 2016;25:162-3 PMID: 27567164.

10. Keskin A, Unalacak M, Bilge U, Yildiz P, Guler S, Selcuk EB, Bilgin M. Effects of Sleep Disorders on Hemoglobin A1c Levels in Type 2 Diabetic Patients. Chin Med J (Engl). 2015;128(24):3292-7 PMID: 26668142.

11. Mok Y, Tan CW, Wong HS, How CH, Tan KL, Hsu PP. Obstructive sleep apnoea and Type 2 diabetes mellitus: are they connected? Singapore Med J. 2017;58(4):179-83 PMID: 28429032.

12. Katsumata K, Okada T, Miyao M, Katsumata Y. High incidence of sleep apnea syndrome in a male diabetic population. Diabetes Res Clin Pract. 1991;13:45-52 PMID: 1773713.

13. Rajan $\mathrm{P}$, Greenberg H. Obstructive sleep apnea as a risk factor for type 2 diabetes mellitus. Nat Sci Sleep. 2015;7:113-25 PMID: 26491377.

14. Nagayoshi M, Punjabi NM, Selvin E, Pankow JS, Shahar E, Iso H, Folsom AR, Lutsey PL. Obstructive sleep apnea and incident type 2 diabetes. Sleep Med. 2016:25:156-61 PMID: 27810258.

15. Soylu AC, Levent E, Sariman N, Yurtlu S, Alparslan S, Saygi A. Obstructive sleep apnea syndrome and anthropometric obesity indexes. Sleep Breath. 2012;16(4):1151-8 PMID: 22139137.

16. Kahn HS. The "lipid accumulation product" performs better than the body mass index for recognizing cardiovascular risk: a population-based comparison. BMC Cardiovasc Disord. 2005;5:26. https://doi.org/10.1186/ 1471-2261-5-26 PMID: 16150143.

17. Xia C, Li R, Zhang S, Gong L, Ren W, Wang Z, Li Q. Lipid accumulation product is a powerful index for recognizing insulin resistance in nondiabetic individuals. Eur J Clin Nutr. 2012;66(9):1035-8 PMID: 22781025.

18. Yan G, Li F, Elia C, Zhao Y, Wang J, Chen Z, Yuan H, Lu Y. Association of lipid accumulation product trajectories with 5-year incidence of type 2 diabetes in Chinese adults: a cohort study. Nutr Metab (Lond). 2019;16:72. https://doi.org/10.1186/s12986-019-0399-7 PMID: 31641369.

19. Bozorgmanesh M, Hadaegh F, Azizi F. Diabetes prediction, lipid accumulation product, and adiposity measures; 6-year follow-up: Tehran lipid and glucose study. Lipids Health Dis. 2010;9(45). https://doi.org/10. 1186/1476-511X-9-45 PMID: 20459710.

20. Wu J, Zhong Y, Yue S, Guan P, Zhang G, Liu L, Chen L. Association between lipid accumulation product and diabetic retinopathy based on a community-based survey in Chinese with type 2 diabetes. Diabetes Metab Syndr Obes. 2019;12:513-8 PMID: 31114279.

21. Zou J, Wang Y, Xu H, Xia Y, Qian Y, Zou J, Guan J, Chen B, Yi H, Yin S. The use of visceral adiposity variables in the prediction of obstructive sleep apnea: evidence from a large cross-sectional study. Sleep Breath. 2019. https://doi.org/10.1007/s11325-019-01980-7 PMID: 31832983.

22. Isono S. Obesity and obstructive sleep apnoea: mechanisms for increased collapsibility of the passive pharyngeal airway. Respirology. 2012;17(1):32-42 PMID: 22023094.

23. Kuvat N, Tanriverdi H, Armutcu F. The relationship between obstructive sleep apnea syndrome and obesity: a new perspective on the pathogenesis in terms of organ crosstalk. Clin Respir J. 2020;14(7):595-604 PMID: 32112481.

24. Du C, He C, Dong L, Zheng S, Wang W, Zheng C, Wang S, Lin M, Yang S, Li $X$, et al. Associations of apnea hypopnea index and educational attainments with microvascular complications in patients with T2DM. Endocrine. 2020; 67(2):363-73 PMID: 31927752

25. Ikeda Y, Kasai T, Kawana F, Kasagi S, Takaya H, Ishiwata S, Narui K. Comparison between the apnea-hypopnea indices determined by the REMstar Auto M series and those determined by standard in-laboratory polysomnography in patients with obstructive sleep apnea. Intern Med. 2012;51((20):2877-85 PMID: 23064561.

26. Huang T, Lin BM, Stampfer MJ, Tworoger SS, Hu FB, Redline S. A PopulationBased Study of the Bidirectional Association Between Obstructive Sleep Apnea and Type 2 Diabetes in Three Prospective U.S. Cohorts. Diabetes Care. 2018:41(10):2111-9 PMID: 30072403.

27. Shaw JE, Punjabi NM, Wilding JP, Alberti KG, Zimmet PZ, International Diabetes Federation Taskforce on Epidemiology and Prevention. Sleepdisordered breathing and type 2 diabetes: a report from the International Diabetes Federation Taskforce on Epidemiology and Prevention. Diabetes Res Clin Pract. 2008;81(1):2-12 PMID: 18544448.
28. McArdle N, Hillman D, Beilin L, Watts G. Metabolic risk factors for vascular disease in obstructive sleep apnea: a matched controlled study. Am J Respir Crit Care Med. 2007;175(2):190-5 PMID: 17068329.

29. Subramanian A, Adderley NJ, Tracy A, Taverner T, Hanif W, Toulis KA, Thomas GN, Tahrani AA, Nirantharakumar K. Risk of Incident Obstructive Sleep Apnea Among Patients With Type 2 Diabetes. Diabetes Care. 2019; 42(5):954-63 PMID: 30862657.

30. Jehan S, Myers AK, Zizi F, Pandi-Perumal SR, Jean-Louis G, McFarlane SI. Obesity, obstructive sleep apnea and type 2 diabetes mellitus: Epidemiology and pathophysiologic insights. Sleep Med Disord. 2018;2(3):52-8 PMID: 30167574

31. Bozkurt NC, Beysel S, Karbek B, Unsal IO, Cakir E, Delibasi T. Visceral obesity mediates the association between metabolic syndrome and obstructive sleep apnea syndrome. Metab Syndr Relat Disord. 2016;14(4):217-21 PMID: 27003688.

32. Vgontzas AN, Papanicolaou DA, Bixler EO, Hopper K, Lotsikas A, Lin HM, Kales A, Chrousos GP. Sleep apnea and daytime sleepiness and fatigue: relation to visceral obesity, insulin resistance, and hypercytokinemia. J Clin Endocrinol Metab. 2000;85(3):1151-8 PMID: 10720054.

33. Laaban JP, Daenen S, Leger D, Pascal S, Bayon V, Slama G, Elgrably F. Prevalence and predictive factors of sleep apnoea syndrome in type 2 diabetic patients. Diabetes Metab. 2009;35(5):372-7 PMID: 19683953.

34. Unal Y, Ozturk DA, Tosun K, Kutlu G. Association between obstructive sleep apnea syndrome and waist-to-height ratio. Sleep Breath. 2019;23(2):523-9 PMID: 30238284

35. Wang $H$, Sun $Y$, Wang $S$, Qian H, Jia P, Chen Y, Li Z, Zhang L. Body adiposity index, lipid accumulation product, and cardiometabolic index reveal the contribution of adiposity phenotypes in the risk of hyperuricemia among Chinese rural population. Clin Rheumatol. 2018;37(8):2221-31 PMID: 29770928.

36. Roriz AK, Passos LC, de Oliveira CC, Eickemberg M, Moreira Pde A, Sampaio LR. Evaluation of the accuracy of anthropometric clinical indicators of visceral fat in adults and elderly. PLoS One. 2014;9(7):e103499. https://doi. org/10.1371/journal.pone.0103499 PMID: 25078454.

37. Kahn HS. The Lipid Accumulation Product Is Better Than BMI for Identifying Diabetes:A population-based comparison. Diabetes Care. 2006;29:151-3 PMID: 16373916

38. loachimescu AG, Brennan DM, Hoar BM, Hoogwerf BJ. The lipid accumulation product and all-cause mortality in patients at high cardiovascular risk: a PreCIS database study. Obesity (Silver Spring). 2010; 18(9):1836-44 PMID: 20035284.

39. Tola EN, Yalcin SE, Dugan N. The predictive effect of inflammatory markers and lipid accumulation product index on clinical symptoms associated with polycystic ovary syndrome in nonobese adolescents and younger aged women. Eur J Obstet Gynecol Reprod Biol. 2017;214:168-72 PMID: 28535403.

40. Fiorentino TV, Marini MA, Succurro E, Andreozzi F, Sesti G. Relationships of surrogate indexes of insulin resistance with insulin sensitivity assessed by euglycemic hyperinsulinemic clamp and subclinical vascular damage. BMJ Open Diabetes Res Care. 2019;7(1):e000911. https://doi.org/10.1136/bmjdrc2019-000911 PMID: 31798905.

\section{Publisher's Note}

Springer Nature remains neutral with regard to jurisdictional claims in published maps and institutional affiliations.

\section{Ready to submit your research? Choose BMC and benefit from:}

- fast, convenient online submission

- thorough peer review by experienced researchers in your field

- rapid publication on acceptance

- support for research data, including large and complex data types

- gold Open Access which fosters wider collaboration and increased citations

- maximum visibility for your research: over $100 \mathrm{M}$ website views per year

At BMC, research is always in progress.

Learn more biomedcentral.com/submission 